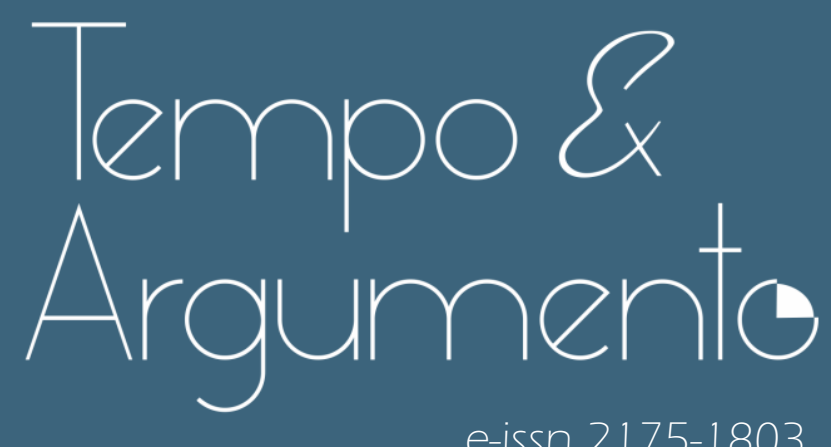

e-issn 2175-1803

O historiador com CNPJ: depressão, mercado de trabalho e história pública

- Pedro Telles da Silveira

Doutor em História pela Universidade Federal do Rio Grande do Sul (UFRGS).

Atualmente realiza Estágio Pós-Doutoral na Universidade Estadual de Campinas

(UNICAMP) com bolsa da Fundação de Amparo à Pesquisa do Estado de São

Paulo (FAPESP), processo no 2019/15223-1.

Campinas, SP - BRASIL

lattes.cnpq.br/9302624475760221

pedrotellesdasilveira@gmail.com

(D) orcid.org/0000-0001-7576-5241

Para citar este artigo:

SILVEIRA, Pedro Telles da. O historiador com CNPJ: depressão, mercado de trabalho e história pública. Tempo e Argumento, Florianópolis, v. 12, n. 30, e0204, maio/ago. 2020.

do) http://dx.doi.org/10.5965/2175180312302020e0204

Recebido: 28/10/2019

Aprovado: 03/06/2020 


\title{
O historiador com CNPJ: depressão, mercado de trabalho e história pública
}

\begin{abstract}
Resumo
Historiadoras e historiadores têm enfrentado uma nova série de tensões na tentativa de justificar o trabalho que realizam. Projetos legislativos, discursos políticos, cortes no financiamento de instituições públicas e privadas, todos eles originam uma situação cada vez mais dificultosa para a prática acadêmica. Não por acaso, os casos de depressão e problemas psicológicos na graduação e pósgraduação começaram a ganhar destaque no debate público. Ao mesmo tempo, temos visto também o crescimento da preocupação com a maneira pela qual historiadoras e historiadores podem legitimar perante a sociedade o que fazem. Uma dessas maneiras é a história pública. A partir dessa situação, o objetivo desta contribuição é defender a necessidade de uma discussão mais ampla sobre trabalho e relações trabalhistas no âmbito da história. Assim, propõe-se que os cursos de graduação e pós-graduação em história assumam postura ativa e, até mesmo, propositiva frente ao mercado de trabalho, através da reconfiguração da identidade profissional de historiadoras e historiadores que a história pública oferece. Dessa maneira, considera-se que a história pública tem papel fundamental para encontrar brechas que permitam superar o diagnóstico concomitante do aumento dos casos de depressão e ausência de perspectivas profissionais, de modo a repensar o que as historiadoras e historiadores fazem.
\end{abstract}

Palavras-chave: História Pública. Mercado de Trabalho. Depressão Mental.

\section{The historian in the private sector: Depression, Job Market and Public History}

\begin{abstract}
Historians today have faced a new series of threats regarding how they justify what they do. New laws, political discourses and overall diminishing funding for public and private institutional have led to a situation in which is increasingly hard to conduct research and have an academic life. Thus, it is not without reason that cases of depression and psychological problem among undergraduate and graduate students have come to the fore in the public realm. At the same time, historians have also tried to find new ways to justify what they do to society. One of these is public history. Considering this context, this contribution's main goal is to defend the need for a broader discussion on work and work relations regarding the historical discipline. It proposes that undergraduate and graduate courses assume a more active posture regarding the job market, what could be made through the rethinking of historian's professional identity with which public history is engaged to. Therefore, public history has a fundamental role in finding breaches that make it possible to overcome the simultaneous processes of the increase in the cases of depression and the lack of professional perspectives. This could lead to reframe what it is that historians effectively do.
\end{abstract}

Keywords: Public History. Job market. Depression. 
Não é exagero dizer que o debate a respeito da inserção social de historiadoras e historiadores adquiriu tons dramáticos nos últimos anos, senão últimos meses, no Brasil. Para além dos discursos que buscam a todo custo deslegitimar o saber histórico produzido nas universidades, através da propagação de publicações falsas, boatos e pela judicialização do saber histórico, é necessário mencionar o anúncio do corte de 5.961 bolsas de iniciação científica, mestrado, doutorado e pós-doutorado pelo CNPq, assim como a redução do orçamento destinado às verbas de custeio das universidades públicas federais no país, no financiamento privado à educação superior - FIES - e no contingenciamento de recursos da Capes, resultando na possibilidade e/ou efetivação de novos cortes e levando à perspectiva de paralisação da ciência no país. Os cortes afetam a sobrevivência material de pesquisadoras e pesquisadores, para os quais, devido às regras de fomento à pesquisa, as bolsas são frequentemente sua única fonte de renda. Dessa maneira, aos ataques simbólicos à relevância do conhecimento científico e à desinformação acerca da prática universitária no país, acrescenta-se o desmanche das condições de possibilidade que, no cotidiano, permitem a milhares de pesquisadoras e pesquisadores se dedicarem as suas áreas de especialidade. Infelizmente, apesar dos planos - ou ilusões - do governo federal, o investimento proveniente de outras fontes no país ainda é escasso e, quando existente, normalmente é oriundo das estatais que o próprio governo pretende privatizar ${ }^{1}$. Se as humanidades sofrem menor pressão financeira quando comparadas a outras áreas, uma vez que dependem de menos recursos do que estas, percebe-se, mesmo assim, a dificuldade em justificá-las num contexto universitário no qual, devido à escassez orçamentária, as pesquisadoras e pesquisadores são lançados numa arena pública para a qual a utilidade imediata e o retorno financeiro de suas pesquisas são os principais critérios para a distribuição do financiamento. Assim, as humanidades - e a história entre elas - se veem cada vez com menos espaço na própria instituição que as abriga, a universidade.

\footnotetext{
Essa situação não é restrita ao Brasil, como foi evidenciado na matéria "Nos países desenvolvidos, o dinheiro que financia a ciência na universidade é público”, de Luiza Caires, publicada no Jornal USP, em 24 de maio de 2019, disponível em https://jornal.usp.br/ciencias/nos-paises-desenvolvidos-o-dinheiro-que-financia-a-ciencia-epublico/.
} 
Esses processos, resultantes de escolhas políticas determinadas, tendem a se confundir com outro movimento, o qual não deixa de ser positivo: o esgotamento e, por que não, o amadurecimento do modelo de expansão universitária que caracterizou a política educacional para o ensino superior no país nos últimos quinze anos. Trata-se de um contexto desafiador, agravado pela situação descrita acima, que exige a reinvenção de historiadoras e historiadores, a batalha por novos espaços de atuação e, ao cabo, a elaboração de uma nova justificativa para o conhecimento histórico, assim como para o ensino superior, no país. Não é à toa que a preocupação com a história pública tem se mostrado como um caminho para a resolução do problema da relevância do conhecimento histórico - se essa promessa se frutificará em resultados concretos ou será apenas uma tendência passageira dos estudos históricos, é algo que ainda precisamos de tempo para determinar.

Também não é por acaso que o diagnóstico do aumento de casos de depressão em cursos de graduação e pós-graduação tenha se tornado tão frequente nos últimos anos. O problema é agravado por condicionantes que, não sendo exclusivamente brasileiras, se tornam mais pesadas em nosso contexto. A frustração decorrente da sensação de que finalmente um ciclo de reprodução social seria quebrado e a educação superior, mesmo em cursos cujas perspectivas financeiras são limitadas - como a história -, seria uma das formas através das quais os filhos teriam acesso a experiências que não estavam disponíveis a seus pais, acentua o impacto que o desinvestimento à educação tem sobre a saúde psicológica de estudantes de graduação e pós-graduação e sobre a configuração social do país.

Ao mesmo tempo, tendo esboçado esse amplo panorama, gostaria de apontar o que parece ser uma ausência no debate a respeito da inserção social do conhecimento histórico: a temática do trabalho e das relações trabalhistas. Historiadoras e historiadores reforçarão sua presença no espaço público sob condições muito diversas daquelas anteriormente existentes e, numa economia para a qual a informação é cada vez mais a principal mercadoria, se tornarão parte do mercado de produção de conteúdo, tarefa para a qual nossos cursos de graduação e pós-graduação pouco os têm preparado. Torna-se necessário 
repensar a atuação de historiadoras e historiadores sob o prisma do trabalho, de modo a conceber novas identidades profissionais enquanto historiadoras e historiadores que atuarão em espaços que não o universitário ou escolar. Essa necessidade é tanto maior quanto, devido às mudanças nas condições de acesso a postos universitários e à deterioração das condições de trabalho na educação básica, mais e mais historiadoras e historiadores escolherão vias alternativas para sua atuação.

"Historiador com CNPJ", essa é uma das identidades que tenho procurado formular para mim, que sou doutor em História e atualmente trabalho numa agência de marketing político. Comparado com muitos colegas, tenho bastante sorte, pois recebo relativamente bem; no momento, trabalho poucas horas, faço meu trabalho em casa e consigo colocar em prática uma série de habilidades que aprendi ao longo de minha formação; por outro lado, sou um trabalhador precarizado, não tenho garantias trabalhistas, preciso indicar meu substituto caso me afaste para atender congressos ou prestar concursos e, por questões de contrato, trabalho todos os dias, domingos e feriados incluídos. Para receber, emito uma nota: sou uma empresa, um microempreendedor individual, pessoa jurídica de mim mesmo. Uma posição que, vale lembrar, pouco pensei que ocuparia ao longo de minha trajetória na graduação e na pós-graduação.

Além de minha experiência pessoal, esta reflexão também é marcada por uma série de encontros com colegas, amigos e amigas, que têm expressado seguidamente o mesmo desconforto, qual seja, como justificar a opção pela universidade e, no caso da pós-graduação, pela academia, num mundo que definitivamente não a estimula. Confrontados com a necessidade de sobrevivência material, muitos se perguntam se o esforço valeu a pena, se o investimento de anos numa formação superior na área das humanidades não foi em vão. "Que fazer?", essa pergunta que animou tanto a ética kantiana quanto a práxis revolucionária leninista e que foi retomada por Hayden White em sua reflexão a respeito do passado prático (WHITE, 2012, p. 22) é feita todos os dias por milhares de estudantes de história que se veem divididos entre o imperativo financeiro e a satisfação de seus desejos de ascensão social por meio do ensino superior. Que fazer? 
Meu propósito é refletir sobre essa situação explorando a intersecção entre mercado de trabalho, os espaços de atuação de historiadoras e historiadores e as pressões psicológicas enfrentadas por elas e eles na tentativa de se manterem historiadoras e historiadores em espaços diversos aos quais sua formação thes preparou. Iniciarei com o que considero ser uma lacuna de teorização, qual seja, a falta de reflexão sobre os modos de atuação de historiadoras e historiadores para além da universidade ou da educação básica. Num segundo momento, faço um desvio em direção ao mal-estar que tem assolado tantas pessoas atualmente, investigando as causas do crescente diagnóstico de depressão. Depois, estudo em maior profundidade as alterações no mercado de trabalho que favorecem esse diagnóstico e que serão encontradas por historiadoras e historiadores quando transitarem da academia à atuação profissional.

Minha intenção não é fazer uma listagem empírica das possibilidades de atuação de historiadoras e historiadores "fora" da universidade ou da sala de aula, mas abrir um espaço de reflexão para essas subjetividades "dentro" da academia. Para isso, será necessário compreender a demanda de sentido que é feita por estudantes de graduação e pós-graduação num cenário de profundas transformações na natureza das relações trabalhistas. Mencionarei minha experiência apenas pontualmente, para ilustrar ou coordenar um ou outro movimento de minha reflexão, que pretende ter caráter teórico e geral. Mesmo assim, dela retiro a consideração de que é necessário encarar, até mesmo de forma propositiva, a relação entre universidade e mercado de trabalho. Não pretendo converter as leitoras e os leitores ao empreendedorismo, mas apontar alguns caminhos de saída para impasses que têm afetado cada vez mais pessoas na mesma situação. Por esse motivo, esta reflexão se encerra com alguns apontamentos que permitirão, assim espero, escapar desses mesmos impasses e restituir o espaço de uma autonomia e felicidade possíveis para historiadoras e historiadores confrontados com a necessidade de pagar suas contas e o desejo de mobilizar seu saber. 


\section{Uma lacuna de teorização}

Existe uma ausência de teorização a respeito da atuação de historiadoras e historiadores "fora" da academia e da educação básica, ainda que a existência desse espaço de atuação seja reconhecida. Para ilustrá-lo, quero remeter a texto recente de Benito Bisso Schmidt. Segundo o autor, já no contexto da redemocratização,

[...] diversos profissionais da história, formados nos métodos da disciplina, optaram, em função de causas diversas, que vão do gosto pessoal à necessidade de sobrevivência, por não atuarem nem como professores nem como investigadores nas poucas instituições para além das universidades voltadas à pesquisa histórica no país (SCHMIDT, 2018, p. 17, grifo nosso)

mencionando a atuação em instituições de memória de órgãos públicos e da iniciativa privada e a criação de empresas de consultoria histórica para "indivíduos e entidades interessadas em constituir narrativas sobre os seus passados com um certo 'selo de qualidade"' (SCHMIDT, 2018, p. 17). Para o autor, a emergência da história pública visa recobrir esse espaço de atuação intermediário, dotando-o de unidade:

Com isso, também emergiu um novo sujeito: o historiador público, e não mais o historiador "diferentão" que, ao contrário da maioria de seus pares, não atua como professor ou pesquisador stricto sensu, mas em espaços públicos e privados variados, como museus, arquivos, memoriais e secretarias de turismo; ou gerenciado websites e blogs; ou assessorando produtoras de cinema e editoras. Sujeito esse que busca espaço, voz e, sobretudo, reconhecimento profissional. (SCHMIDT, 2018, p. 18)

Não obstante se tratar de um movimento internacional, é necessário pensar a difusão recente da história pública no Brasil tendo em mente o debate em torno da regulamentação da profissão de historiador. O projeto de lei a esse respeito, do qual o próprio Benito Schmidt foi um dos principais defensores durante sua gestão à frente da ANPUH, entre 2011 e 2013, previa a presença de historiadoras e historiadores em órgãos públicos; a regulamentação de concursos e atividades como organização de acervos e preparação de informações para publicação; planejamento e implementação de serviços de pesquisa histórica; assessoramento de serviços de documentação e acesso à informação histórica; auxílio na elaboração de políticas de preservação 
documental, incluindo o descarte de documentos; e a "elaboração de pareceres, relatórios, planos, projetos, laudos e trabalhos sobre temas históricos" (SCHMIDT, 2018, p. 22). Como destaca o autor, não se trata de garantir exclusividade às historiadoras e aos historiadores no mercado historiográfico, tampouco no espaço público, mas de assegurar uma reserva através da qual, no contexto altamente regulamentado das profissões no país, aquelas e aqueles que são formados em história possam exercer seu saber.

Se a inércia parlamentar e a crise política haviam interrompido a tramitação do projeto de lei, mais recentemente o presidente Jair Bolsonaro optou por vetá-lo integralmente, levando a discussão legislativa sobre a regulamentação da profissão de historiador de volta à estaca zero. Mesmo assim, será que o debate a respeito da profissionalização mantém o mesmo significado caso se considere o contexto de forte desregulamentação da legislação trabalhista no país? Nos últimos anos, assistimos à aprovação da Reforma Trabalhista, da Reforma da Previdência e, mais recentemente, da medida provisória da Liberdade Econômica. É necessário recordar que o projeto de lei não prevê situações como a minha, cada vez mais comuns, nas quais os trabalhadores se transformam em empresas.

Essa situação reforça a convicção de que a discussão sobre a história pública tem de levar em conta o desenho contemporâneo das relações entre público e privado - mais importante ainda, essa discussão precisa levar em consideração o papel do Estado na desregulamentação do trabalho, fornecendo lastro institucional ao enfraquecimento dos direitos trabalhistas. Retornarei a esse aspecto mais tarde; por ora, no entanto, creio necessário afirmar que não é mais possível continuarmos a opor o mercado e o Estado, principalmente porque um trabalha a serviço do outro. Isso não implica que a dimensão estatal não seja um campo de disputa, como atestam os debates legislativos recém mencionados.

Enquanto isso, a ampliação do campo de atuação de historiadoras e historiadores apontou a história corporativa como uma das profissões do futuro. Em publicação do jornal O Estado de São Paulo, afirma-se que, "Quem gosta de história e não quer mergulhar na academia nem dar aulas pode pensar em 
trabalhar com memória institucional" (ZANDONADI, 2015, grifo nosso). Nesse caso, as historiadoras e historiadores se tornam importantes para empresas que desejam tanto uma melhor gestão de seus acervos até a narração de suas trajetórias; elas e eles atuam em equipes diversas, uma vez que

Os guardiões da memória das organizações surgem de escolas variadas e compõem times multifacetados. São pesquisadores e escutadores talentosos. Entretanto, há desde os que dominam os métodos da coleta de depoimentos por meio de história oral aos que preferem se concentrar no minucioso trabalho de arquivo. Juntos e à parte, jornalistas, arquitetos, arquivistas, relações públicas, antropólogos, sociólogos, museólogos, bibliotecários e especialistas na conservação de objetos e documentos dedicamse a construir narrativas. (ZANDONADI, 2015, sem paginação)

Depreende-se que as historiadoras e os historiadores, para esse segmento do mercado, são profissionais valorizados, uma vez que aliam as habilidades técnicas às competências analíticas, tendo a capacidade de formular um "produto histórico" completo, ainda que dificilmente sejam seus autores isolados. Segundo uma das entrevistadas na reportagem, Carla Nieto Vidal, que trabalha no campo desde a década de 1990, o dilema que os estudantes enfrentavam era o de que

[...] quase não havia campo de trabalho para o historiador e o mundo empresarial trazia novas possibilidades de atuação. Por outro lado, caía sobre essa atuação uma cortina de preconceito, uma crítica, como se fosse uma "concessão ao capital" (ZANDONADI, 2015, sem paginação).

Independente do peso que se conceda a ele, o dilema aponta que, tanto na década de 1990 quanto agora, o problema da inserção de historiadoras e historiadores em novos espaços de trabalho - esse âmbito do "nem... nem" que já fez sua aparição nas citações recolhidas aqui - lança em questão a própria justificativa da história em meio a condicionantes sociais diversos, entre eles o mercado.

O campo dos serviços em história foi abordado recentemente por Rodrigo Turin, em texto sobre as figurações de historiadora e historiador na contemporaneidade. Para ele, o dilema novamente se apresenta, pois é benéfico

[...] oferecer os chamados "serviços em história" ou, mais exatamente, em "memória", adequando-se às demandas de um mercado cada vez mais acelerado e flexível? Em que medida [...] 
essas novas demandas externas sociopolíticas não implicam o esvaziamento dos critérios internos, disciplinares, legados por sua tradição? É em torno dessas questões que a comunidade historiográfica parece estar procurando encontrar uma nova inserção em seu presente. (TURIN, 2018, p. 192)

Turin critica que a questão esconde uma ausência de alternativas, pois a historiografia disciplinar se vê obrigada ou a adotar o linguajar empresarial proposto ou a reforçar os critérios da avaliação acadêmica, defendendo sua autonomia. Entretanto, o autor também lembra que os parâmetros da autonomia universitária são corroídos por dentro, a partir da adoção e/ou imposição de um conjunto de práticas que enfatizam a medição do desempenho e se orientam pelos valores da "eficiência" e "excelência", perfazendo o campo da transformação neoliberal da educação superior.

Ainda que concorde com as ressalvas apresentadas por Rodrigo Turin, acredito que seu diagnóstico não faz justiça às oportunidades apresentadas a historiadoras e historiadores hoje, sobretudo se pensarmos no panorama introduzido pela história pública. A esse respeito, cabe indagar se o significado das transformações mencionadas é o mesmo para historiadoras e historiadores que estão efetivamente empregados na academia, principalmente como professores, e as situações muito diversas daquelas e daqueles que são graduandos e pós-graduandos, para não mencionar o amplo escopo de profissionais que atuam justamente nos "serviços em história". Desqualificá-los pelo constrangimento que sofrem do mercado ou acreditar que o conhecimento acadêmico perde sua qualidade se inserido em outras redes de produção, muitas delas vinculadas à iniciativa privada, não deixa de remeter ao dilema apontado ainda na década de 1990, quando levantava o fantasma de "vender-se" ao capital.

Da mesma forma, ainda que atrelar a avaliação da atuação acadêmica à quantidade de publicações - ou à medição de seu impacto - seja uma prática discutível, ela tem pesos diferentes para graduandos e pós-graduandos que pretendem ingressar no sistema universitário e professores já estabelecidos. Não se trata de aceitar o que já existe como dado, mas de compreender que dinâmicas de resistência, como "greves de publicação", não superam as linhas de tensão da hierarquia acadêmica. Num caso, pode penalizar a pesquisadora ou 
pesquisador com a perda de uma bolsa de produtividade - financeiramente, a perda de um acréscimo ao salário total -; no outro, pode retirar os pontos decisivos para a aprovação num mestrado, doutorado ou concurso - e, por conseguinte, uma redução drástica ou a perda de uma fonte de renda significativa num orçamento já apertado, levando até mesmo ao abandono da academia.

O neoliberalismo foi implantado de maneiras diferentes de acordo com o local e a época - e o mesmo pode ser dito de seu impacto social, pois se alguns se beneficiaram, outros tantos perderam. Para a reflexão que proponho aqui, é necessário reconhecer que o que no texto de Rodrigo Turin ainda é resistência, para mim, que sou historiador com CNPJ, é um ponto de partida. Minha condição só existe pelo cruzamento entre o neoliberalismo e o meu conhecimento, que é acadêmico.

\section{Uma crise de subjetividade}

Ainda que não seja possível atribuir-lhe exclusivamente a responsabilidade, a falta de uma identidade profissional enquanto historiadoras e historiadores para a crescente massa de alunas e alunos que não ocupará uma vaga nos programas de pós-graduação, ou se tornará professora e professor, é um dos motivos por detrás da abertura do espaço de discussão sobre o impacto subjetivo e as pressões psicológicas da vida universitária. Confrontados com a ausência de opções, muitas deles se veem confrontados com o receio de "abandonar" a academia, o que também implica - para muitos - deixar de lado o sonho da ascensão social através da formação universitária. Essa estagnação conecta a experiência das universitárias e universitários à dos trabalhadores precarizados, como desenvolverei na terceira seção deste artigo.

O problema se agrava devido à mutabilidade das identidades profissionais na contemporaneidade. O que significa ser historiadora ou historiador quando as identidades profissionais não são fixas e estão em constante mudança, resultado da própria necessidade de aperfeiçoamento e atualização dos profissionais que as exercem, para não mencionar a precariedade das relações trabalhistas? E, por conseguinte, qual o sentido da formação universitária quando os trabalhos se transformam em jobs, isto é, atividades temporárias cuja recompensa em termos 
de formação é cada vez mais adiada, senão impedida, pela premente necessidade de sua realização? Dotados de uma formação, mas não de uma profissão, as egressas e egressos dos cursos de história veem o tempo lento e linear do estudo ser desafiado pelo caráter repetitivo e acelerado do mercado de trabalho. Nas páginas que se seguem, quero sugerir o nexo entre a reconfiguração neoliberal da subjetividade e a ausência de sentido confrontada pelas alunas e alunos a respeito de sua formação.

As transformações ocasionadas pela introdução do neoliberalismo na universidade já são conhecidas e começam a acumular uma bibliografia considerável. Mecanismos de medição, performance, impacto socioeconômico atrelado à obtenção de recursos para pesquisa, excelência, utilitarismo e crescente endividamento dos estudantes são todas características já tratadas por diversos autores (LORENZ, 2012; NUSSBAUM, 2016; SHORE; TAITZ, 2012). Para além dessas práticas, no entanto, considero importante refinar a compreensão de neoliberalismo que está em jogo, que não é apenas uma política econômica, mas uma racionalidade, no sentido de um conjunto de enunciados que efetiva aquilo que Michel Foucault chamou de "governo dos homens". Trata-se de uma série de relações de poder que orientam o mundo intersubjetivo, instituindo mecanismos disciplinares cujo principal resultado é o sujeito. Assim, o que o neoliberalismo produz são subjetividades conforme sua própria lógica; não é por acaso que o investimento em si e a compreensão das relações sociais pelo prisma da economia sejam seus aspectos mais proeminentes. A crise enfrentada pelos estudantes mencionados acima é, a seu modo, uma crise de subjetividade (LAZZARATO, 2014, p. 14).

O neoliberalismo realiza a fusão de esferas que, de acordo com a narrativa filosófica da modernidade, estavam separadas. Um exemplo é a relação entre conhecimento e lucro, uma vez que o saber universitário foi justificado seja pelo serviço à nação, seja pela formação individual, contribuindo para o exercício da cidadania e o fortalecimento da esfera pública. Na ordem neoliberal, prevê-se, primeiro, a redução da pluralidade inerente ao sujeito, suprimindo a distância que possibilitava, caso pensemos na formação histórica moderna ou no contexto de regimes autoritários, a distinção entre a crença pessoal e os atos realizados (KOSELLECK, 1999); ao contrário disso, o que vemos é a demanda da identidade 
de si consigo, como na pressão por transparência e coerência resultante da acumulação de registros nas redes sociais (TURKLE, 2005; EHRENBERG, 2010). Depois, o neoliberalismo aplica uma torção a esse processo, através da identificação entre a subjetividade e formas do capitalismo contemporâneo, mormente a empresa, reforçando a introdução de uma racionalidade econômica por trás dos vínculos sociais. Como afirmam dois de seus melhores anatomistas, Pierre Dardot e Christian Laval,

Trata-se agora de governar um ser cuja subjetividade deve estar inteiramente envolvida na atividade que se exige que ele cumpra [...]; trata-se de ver nele o sujeito ativo que deve participar inteiramente, engajar-se plenamente, entregar-se por completo a sua atividade profissional. (DARDOT; LAVAL, 2017, p. 326)

Uma terceira característica é a responsabilização do sujeito pelo seu sucesso, o que também traz a necessidade de auto-superação, considerada requisito para a felicidade. Assim, se formações subjetivas anteriores eram castradoras por repressão, a atual é problemática por permissão. “Exige-se do novo sujeito", escrevem Dardot e Laval, "que produza 'sempre mais' e goze 'sempre mais' e, desse modo, conecte-se diretamente com um 'mais-de-gozar' que se tornou sistêmico." (DARDOT; LAVAL, 2017, p. 355).

Em sua breve formulação a respeito da contemporaneidade, Byung ChulHan avalia esse processo como a transição da sociedade disciplinar para a "sociedade do desempenho". Enquanto aquela "ainda está dominada pelo não", esta é marcada por uma positividade generalizada, associada à ideia de potência, traduzida mercadologicamente pela disponibilidade de diversas opções à escolha do usuário. Em contrapartida, se a sociedade disciplinar "gera loucos e delinquentes", indivíduos fora do sistema, a sociedade do desempenho, que tudo engloba, "produz depressivos e fracassados" (HAN, 2019, posição 168). A relação entre neoliberalismo e depressão é explicitada na leitura da psicanalista Maria Rita Kehl, para quem "O imperativo do gozo que circula nas sociedades capitalistas do século XXI não aboliu a dívida simbólica nem anulou a principal características do sujeito da psicanálise - o conflito psíquico"; desse modo,

[...] a equivalência entre os ideais de felicidade e a supressão do conflito constrói a perspectiva fantasiosa de que o sujeito possa se tornar idêntico a si mesmo, anulando sua divisão originária. 0 empobrecimento da vida subjetiva que resulta das diversas 
estratégias contemporâneas de anulação do conflito - seja por via medicamentosa ou pela adesão sem reservas às ofertas de gozo em circulação no mercado - é cúmplice do atual crescimento dos casos de depressão. (KEHL, 2015, p. 217)

Como destaca a autora, "na origem do sujeito depressivo não se encontra a falta da falta, que caracteriza a angústia psicótica, mas a insuficiência da ausência" (KEHL, 2015, p. 238). No caso, a ausência oferece a oportunidade de formação de uma potência do imaginário que se encontra impedida quando ela não é intensa o suficiente. Vertida em termos sociais, isso significa a ausência de conflitos que colocavam em lados opostos grupamentos sociais diversos, que eram os vetores de formação de identidade - os trabalhadores, por exemplo. Isso não significa que a sociedade neoliberal não seja atravessada por tensões e violência, mas que esta "não parte mais de uma negatividade estranha ao sistema. É antes uma violência sistêmica, uma violência inerente ao sistema" (HAN, 2019, posição 121). O principal resultado é o esvaziamento do mundo comum. Como descreve Maria Rita Kehl,

[...] apesar de todo o esforço ideológico em sustentar o laço social contemporâneo na base de convocações ao desempenho individual, apagando com isto a dimensão conflitiva da vida em sociedade, ainda assim o espaço público é atravessado por várias dimensões de conflito. O que a crença individualista produz é justamente o oposto do apaziguamento da vida social com base em que "cada um cuide da sua vida e não se preocupe com a do outro". Quando conflitos de interesse entre classes sociais ou tendências políticas passam para o segundo plano, o espaço público tende a se tornar o palco de uma luta, que pode ser mais ou menos violenta, de todos contra todos. (KEHL, 2015, p. 270)

A depressão é um dos resultados, uma espécie de reverso da subjetividade contemporânea, que ocupa seu verso. Formulada a partir do neoliberalismo, falta estabelecer sua relação com os sentidos do trabalho na contemporaneidade e, mais especificamente, com a transformação da universidade nas últimas décadas. O trabalho atualmente não produz mundo ou, ao menos, produz mundos intersubjetivos cada vez menores, como demonstrado pelas redes sociais. O trabalho neoliberal - e sobre isso tratarei logo na próxima seção escapa, portanto, à dimensão emancipadora que ele assumia nas leituras marxistas da realidade social. 
Mas, e quanto à universidade contemporânea? Wendy Brown é certeira quando afirma que é toda a ideia "de que a educação superior pública é um meio para diminuir a desigualdade e aumentar a mobilidade social, assim como um instrumento necessário para alcançar uma democracia com cidadãos cada vez melhor educados [...]" (BROWN, 2015, p. 184) que está em jogo; em seu lugar, a "educação pública superior, assim como todo o resto na ordem neoliberal, é cada vez mais estruturada para aumentar e não para suprimir as trajetórias de classe" (BROWN, 2015, p. 184). No Brasil, esse intervalo foi menor, correspondendo à formação da atual configuração universitária, na qual mais da metade dos estudantes de instituições de ensino superior públicas são oriundos da escola pública, de baixa renda e/ou negros. Ainda assim, essa constatação não estabelece a causa do mal-estar contemporâneo.

“Afinal, do que é que estamos tão esgotados?”, pergunta Peter Pál Pelbart (2013, p. 19). Ou, melhor, por que o esgotamento é uma saída tão característica da vida que atualmente levamos, inclusive na universidade? Para o autor,

O esgotado é aquele que, tendo esgotado seu objeto, se esgota ele mesmo, de modo que essa dissolução do sujeito corresponde à abolição do mundo. Se o cansado tem sua ação comprometida temporariamente, prestes a retomá-la, o esgotado, em contrapartida, é pura inação, testemunho. Sua postura típica não é a do homem deitado, mas do insone sentado, cabeça entre as mãos [...] (PELBART, 2013, p. 39-40)

A imagem é significativa, ainda mais por associar o esgotamento à insônia, isto é, ao rompimento dos ciclos de vida naturais. Ora, como apontou Jonathan Crary, a crescente apropriação capitalista das funções biológicas vitais, inclusive do sono, resulta na "renúncia absoluta à pretensão de que o tempo possa estar acoplado a quaisquer tarefas de longo prazo, inclusive fantasias de 'progresso' ou desenvolvimento", isso porque "Um ambiente 24/7 aparenta ser um mundo social, mas na verdade é um modelo não social, com desempenho de máquina - e uma suspensão da vida que não revela o custo humano exigido para sustentar sua eficácia." (CRARY, 2014, p. 18-19).

Assim, se Pelbart consegue entrever na contraluz da negatividade a abertura de uma positividade no esgotamento, através de sua aproximação ao niilismo e sua potência de questionamento, Crary (2014) já sugere que mesmo o 
esgotamento é apropriado e instrumentalizado na contemporaneidade. É preciso pensar, então, no que significa trabalhar e quem efetivamente trabalha na contemporaneidade, de modo a reestabelecer a proximidade com perspectivas de futuro que gravitam para cada vez mais longe do presente.

\section{Historiador, trabalhador precarizado?}

Antes de iniciar, gostaria de apontar um aspecto que comumente passa despercebido na preocupação com o aumento dos casos de depressão na universidade. Para além da ausência de perspectivas de futuro, encontra-se também o que pode ser uma figura mais próxima e imediata da disjunção subjetiva que é resultante, apesar do contexto atual, da falta de conflito que caracteriza a sociedade neoliberal. Nunca o trabalho, no geral, se aproximou tanto das figurações do trabalho acadêmico, ao menos nas humanidades, que justamente o colocavam à parte do mundo das relações contratuais. Com exceção da pressão por produtividade, trabalhar por demanda, principalmente perto do término dos prazos, para satisfação pessoal e governando o próprio tempo, constitui a experiência acumulada de séculos de estudantes ao redor do globo. Tudo isso faz parte do que constituía certo ethos boêmio que distinguia a vivência universitária como um tempo especial, delimitado pelo ingresso, em seu início, e pela formatura, em sua conclusão, mas passível de ser prolongado num mestrado ou doutorado ou, no caso de se tornar professor, para a vida toda. Era parte da experiência da juventude, anterior à maturidade e ao mundo adulto, este por sua vez associado ao trabalho. Além disso, como assinalou Enzo Traverso (2016), a boemia era parte essencial, ainda que conflitiva, de uma visão de mundo associada - em sentido amplo - à esquerda, quando não seja pelo nãoconformismo que ela implica. Hoje, entretanto, ficar acordado até de madrugada é o normal, o sucesso é "disruptivo", a palavra "revolução" foi cooptada pelo signo da inovação, de modo que é como se esse potencial não-conformista não tivesse por onde extravasar, com exceção da própria universidade. Estranhamente, uma vez que o mundo e o campus cada vez mais se aproximam, era para estarmos felizes, mas não estamos.

Não por acaso, campus é como são denominados os núcleos de trabalho das grandes empresas de tecnologia - Apple, Facebook, Google -, elas também oriundas do convívio universitário norte-americano. A denominação envolve uma 
reconceituação da relação dessas empresas com o espaço urbano, ancorada numa transformação radical da natureza do trabalho. Analisando um desses campi em 2012. Alexandra Lange já apontou que o imaginário das empresas de tecnologia replica arquitetonicamente práticas do urbanismo, como a existência de ruas, centros comerciais e áreas de uso diverso, porém de forma controlada, isolada e privatizada. "Essas companhias", escreve a autora, "são ithas; e as lojas de suas ruas principais são acessíveis apenas àqueles que ostentam um crachá corporativo” (LANGE, 2012, posição 77). A motivação por detrás dessa configuração do espaço empresarial é "atrair talentos, fomentar lealdade, encorajar os empregados a passar mais tempo no trabalho e, logo, aumentar a produtividade." (LANGE, 2012, posição. 97). Urbanismo e práticas de trabalho se reforçam mutuamente, ambas a serviço da empresa que os coordena; o resultado é a interpenetração do trabalho com todas as esferas da vida, pública ou privada:

Quanto mais amenidades existem no campus, menor é a necessidade de deixá-lo e mais tempo os funcionários permanecem. Quanto mais eles permanecem, mais trabalho têm para fazer. Quanto mais aberto o escritório, quanto mais variados e chamativos seus espaços e refeitórios, mais encontros eles terão. E quanto mais encontros eles tiverem, mais longa será a corrente da inovação. (LANGE, 2012, posição. 314)

O que se passa nas grandes empresas de tecnologia parece alheio ao nosso tema, mas toca numa de suas questões centrais, qual seja, o destino do trabalho intelectual na discursividade neoliberal. O exemplo das empresas de tecnologia demonstra até que ponto elas estão dispostas a reconfigurar a relação entre vida e trabalho - cuja aproximação é um dos princípios do próprio neoliberalismo -, de modo a enquadrar a constante necessidade de, por um lado, "disciplinar seus trabalhadores altamente qualificados e criativos, extrair deles sua propriedade intelectual, simplificar seus processos de trabalho e padronizálos de acordo com o 'gerenciamento do saber' e o 'controle de qualidade'”, e, por outro lado, "mantê-los motivados e encorajar o fluxo de novas ideias e a manutenção da excelência no trabalho" (HUWS, 2014, sem paginação). Nesse processo, alguns trabalhadores conseguem uma posição vantajosa frente a seus empregadores; mas a submissão da vida ao trabalho produz também, como diria Han, seus depressivos e fracassados. 
A erosão dos laços de solidariedade entre os trabalhadores tem sido tema há algum tempo da sociologia, no geral, e da sociologia do trabalho, em particular. O debate tem ampla penetração no Brasil e tanto no contexto nacional quanto internacional ele gira em torno do questionamento da pertinência da classe trabalhadora enquanto categoria de análise e experiência social ou, pelo contrário, sua dissolução e substituição por outra classe. Nos últimos anos, a partir do trabalho de Guy Standing (2013), tem-se falado em precariado para descrever a situação dos novos trabalhadores que, na virtual ausência de direitos trabalhistas, estão sujeitos a contratos intermitentes ou instáveis e são frequentemente autoempregados, mesmo quando trabalham para alguém. A condição varia de acordo com os diferentes contextos jurídicos, mas se ela tem como exemplo paradigmático o trabalhador da Uber, também contempla aqueles em posição relativamente vantajosa - como eu - que são, para utilizar a legislação brasileira, microempreendedores individuais. Todos estão engajados no investimento de si, quando não seja pela necessidade de financiar o próprio trabalho, o que faz a noção deslizar do caráter abstrato para a realidade tangível do cotidiano - se meu computador estraga, deixando-me sem meu principal instrumento de trabalho, ninguém me auxiliará a comprar outro.

Não quero entrar nas minúcias do debate ${ }^{2}$, que é mais específico ao marxismo, mas apontar que, no contexto brasileiro, apesar das diferentes tendências de análise, parece existir certo consenso de que se trata mais da continuidade da classe trabalhadora que do surgimento de uma nova classe, o precariado ${ }^{3}$. Considero especialmente útil a categoria de "novo proletariado de serviços", elaborada por Ricardo Antunes, por meio da qual é possível perceber a expansão do proletariado inclusive a setores, como o de serviços, que não o

\footnotetext{
Estou ciente da distância entre os autores citados na última seção e os que participam do debate mencionado. A diferença entre ambos reside na compreensão do capitalismo. Assim, no debate que analisarei, o capitalismo é abordado a partir das suas relações de produção, enquanto para os autores da segunda seção deste artigo, com variados graus de filiação ao pensamento de Gilles Deleuze, pode-se dizer que, no capitalismo, "a produção apreende e explora algo mais profundo e transversal à sociedade tomada em conjunto: o processo de singularização e produção de novos modos de subjetivação centrados no desejo" (LAZZARATO, 2014, p. 49). Produção ou desejo (consumo), considero ambas as perspectivas válidas e, espero mostrar aqui, o diálogo entre ambos não é apenas possível como frutífero.

Por exemplo, no trabalho de Ricardo Antunes (2018), citado extensivamente aqui, e que se vale do marxismo; conclusão semelhante chegou Jessé Souza (2010), de inspiração weberiana, ao tratar da questão de se os batalhadores são uma classe média emergente ou uma nova classe trabalhadora; da mesma forma, Thays Wolfarth Mossi (2016), a partir da sociologia de Luc Boltanski, também se inclina nessa direção.
} 
englobavam anteriormente (ANTUNES, 2018, posição 501). O conceito permite compreender, no vocabulário marxista, que o setor de serviços também gera mais valor, ainda que não exerça trabalho produtivo, uma vez que seus produtos têm valor de uso, e muito raramente de troca (HUWS, 2014).

Assim, para Antunes. "as mais distintas modalidades de trabalho presentes no capitalismo contemporâneo vêm [...] ampliando as formas geradoras de valor" (ANTUNES, 2018, posição 566) e, logo, "todos os espaços possíveis se tornaram potencialmente geradores de mais-valor" (ANTUNES, 2018, posição 570). Isso se manifesta na crescente "flexibilidade" das relações trabalhistas, "sem jornadas pré-determinadas, sem espaço laboral definido, sem remuneração fixa, sem direitos" e cujos resultados - as "metas" - são também passíveis de alteração e crescimento contínuo (ANTUNES, 2018, posição 629). Dessa forma, pode-se inverter a perspectiva e sugerir que, no contexto atual, a precarização aumenta o contingente de trabalhadores, mesmo que não exista uma identidade social compartilhada entre eles. Autônomos e freelancers, vale destacar, são ambos trabalhadores sujeitos ao mesmo processo de diminuição gradativa de seus direitos, porém se situam em posições muito distintas na hierarquia social do trabalho. Para além disso, a precarização também corrói as fronteiras entre as classes que dependem do trabalho. Isso é especialmente significativo para a classe média e seu principal signo de distinção social, a formação.

Voltando ao exemplo do autônomo e do freelancer, sua posição distinta na hierarquia social do trabalho é devido à prevalência, no que diz respeito ao último, do trabalho intelectual e especializado. Assim, o autônomo é dotado de um saber prático e relativamente acessível - um curso técnico, por exemplo -, enquanto o freelancer tem uma trajetória mais restrita social e epistemicamente, a qual normalmente inclui um curso superior (e outros cursos de formação continuada). Entretanto, a fronteira entre trabalho especializado e nãoespecializado não é estanque. O exemplo da informática é ilustrativo, pois ela passou de conhecimento restrito a requisito básico de parcela significativa das ocupações hoje. E, com isso, os caminhos da ascensão social voltam a se fechar de acordo com os contornos de classe - parte da informática ainda é de acesso restrito, como a programação, vinculada aos cursos de ciência da computação; outra parcela é de amplo acesso, como os cursos técnicos. 
Acredito que o exemplo sirva de analogia para o problema da relevância dos diplomas de formação superior no Brasil contemporâneo. Não se trata apenas do reconhecimento do papel que as cotas étnico-raciais tiveram no alargamento do espectro social das alunas e alunos que frequentam a universidade, o que por si só é positivo, mas também de constatar que a expansão da rede privada transformou a obtenção de um diploma numa realização corriqueira. Destituída de seu papel de distinção, a formação universitária é menos o catalisador de uma nova experiência social que o prérequisito para empregos um pouco mais dignos, se eles estiverem disponíveis. Nesse quadro, retornam as diferenciações de classe, uma vez que instituições distintas atendem segmentos sociais diversos, trajetória que se reproduz no acesso aos programas de pós-graduação, o que sustenta a relevância da extensão das cotas étnico-raciais também para uma segunda etapa da formação superior. Seja como for, o valor associado à formação universitária diminui e, por conseguinte, em vez de garantir que o diploma seja instrumento de ascensão social, usualmente através da entrada na classe média, vemos que isso não ocorre, até mesmo porque a própria classe média sofre "um intenso processo de proletarização" (ANTUNES, 2018, posição 1007). Por causa da precarização, todos são empurrados para baixo, comprimidos pela necessidade do trabalho.

Ainda que os egressos e egressas dos cursos de história não ocupem a mesma posição que os funcionários de call-centers, telemarketing, TICs, hotelaria, shopping centers, hipermercados, redes de fast food e no comércio, todos exemplos citados por Ricardo Antunes, cabe-lhes a mesma questão, pois, tal como os trabalhadores de serviços, são elas e eles parte da classe média emergente ou do novo proletariado de serviços? Para aquelas e aqueles que escolhem o ensino como ocupação, é fácil perceber que a docência na educação básica já é marcada pela precarização; para quem escolher caminhos "alternativos", existem poucos levantamentos que possam contribuir para uma avaliação qualificada ${ }^{4}$.

\footnotetext{
${ }^{4}$ Um dos poucos estudos sobre o tema foi feito pela American Historical Association com a trajetória profissional dos graduados em história nos Estados Unidos entre 2004 e 2013. Os resultados estão disponíveis sob a forma de banco de dados interativo em https://www.historians.org/wherehistorianswork.
} 
Independentemente do tipo de vínculo empregatício que elas e eles possuírem - concursados em instituições de memória, consultores freelancer de veículos de comunicação, empregados da iniciativa privada, dependentes de editais público -, uma breve menção ao impacto das tecnologias digitais sobre o trabalho de historiadoras e historiadores sugere algumas pistas da feição que ele assumirá. Para Anita Lucchesi, por exemplo,

Pela facilidade de transporte, manuseio e autonomia de bateria, os tablets e e-readers aumentam ainda mais a flexibilidade dessas novas condições de trabalho. Alguém que, por exemplo, analise documentos disponíveis em versões digitais, pode, sem problemas, "transportá-los" nos seus dispositivos móveis para qualquer lugar. Além disso, é possível ler, sublinhar, anotar e ainda compartilhar isso, se comunicar com outras pessoas, ler e-mails etc., a partir de qualquer cômodo da casa, na rua, no trânsito, vai depender da concentração, disposição e estilo de cada um. Sem dúvida, essas são mudanças qualitativas no dia a dia de trabalho de uma pessoa que, antes, ficava restrita no mais das vezes, ao trabalho solitário em arquivos, bibliotecas ou escritórios pessoais. (LUCCHESI, 2014, p. 48)

Por mais correta que seja, a descrição não mimetiza os discursos e as práticas contemporâneas do trabalho? Não importa quando ou onde, as historiadoras e os historiadores estarão sempre trabalhando.

Antes de encerrar esta seção, vale destacar que, se historiadoras e historiadores serão parte do novo proletariado de serviços, e não da classe média emergente, então se percebe a insuficiência de condenar sua adaptação - assim como dos cursos universitários - aos "serviços em história". Essa condenação, ao se prender demasiadamente à academia, perde de vista o mundo do trabalho, pois serviços é justamente o que historiadoras e historiadores farão.

\section{Um plano de ação}

À pergunta realizada na introdução deste artigo - "Que fazer?" - pode-se acrescentar algumas qualificações: que fazer se os sentidos do trabalho intelectual não são os mesmos de antigamente? Que fazer se vemos o rompimento de um contrato de trabalho caracterizado pela artesania e individualidade - um métier - e sua substituição por outro, mais "profissional"? Que fazer se a obtenção da formação universitária não garante nem a 
estabilidade financeira nem o prestígio social que antes ela possibilitava? Que farão as graduadas e graduados dos cursos de história que terão conhecimento, mas não emprego?

Ainda que não tenha o propósito de responder a essas perguntas, a história pública tende a adotá-las devido à problematização dos lugares de atuação que se abrem para historiadoras e historiadores no diálogo com a esfera pública. Mesmo assim, é necessário saber, para lembrar o título de uma coletânea recente, que história pública queremos, especialmente se ela deve atender ao contexto brasileiro.

Para nossa discussão, é interessante lembrar que, segundo os relatos mais tradicionais, a história pública surgiu em meados da década de 1970 na Universidade da Califórnia em Santa Barbara como uma reação à crise de emprego entre os recém-graduados em história, além de se instituir como forma de responder ao desejo, "por parte de historiadores que trabalhavam fora da academia, de uma identidade profissional de historiador reconhecida" (SHOPES, 2016, p. 72-73). Embora a história pública tenha se desenvolvido para além da mera reivindicação de postos de trabalho, articulando uma série de práticas e conceitos ao seu redor, é importante frisar que o desenvolvimento da história pública e a profissionalização das historiadoras e historiadores são processos relacionados. Nos Estados Unidos, isso resultou na criação de cursos de especialização em história pública, muitos deles voltados ao mercado de trabalho e a cargos oriundos da atuação da sociedade civil no contexto norteamericano, como associações comunitárias, movimentos sociais e diferentes setores da administração pública; outras possibilidades estão relacionadas à iniciativa privada. Em todos esses casos, demonstra-se a existência de uma interrelação entre conhecimento especializado e mercado de trabalho que dificilmente é reproduzida no Brasil.

As especificidades da história pública brasileira foram discutidas recentemente por Ricardo Santhiago (2018). Tratando da expansão global da história pública, fenômeno que ocorre mais ou menos concomitantemente no Brasil e na Europa ao longo da última década, após já ter se consolidado nos países de língua inglesa, Santhiago mostra como a história pública adquire 
feições específicas de acordo com o contexto. No Brasil, a história pública escaparia ao caráter pragmático, normativo e, pode-se dizer, utilitarista de sua matriz norte-americana, para ser "ativada como um dispositivo conceitual capaz de ajudar o historiador a enfrentar os desafios contemporâneos de sua atividade"; assim, a história pública é uma "categoria deflagradora de um exercício de retrospecção” (SANTHIAGO, 2018, p. 294), e não um campo profissional delimitado.

Não obstante concordar que a história pública não possa ser reduzida à dimensão utilitária, associada a uma pedagogia normativa, tal como nos Estados Unidos, penso se a formulação de Santhiago não é, para utilizar uma expressão ao gosto das historiadoras e historiadores públicos, restrita aos "muros da academia" e pertinente apenas àquelas e àqueles no seu interior. Por mais que a reflexão deva acompanhar o trabalho de qualquer profissional, ainda mais no caso de um saber com forte carga teórica, como o histórico, não acaba sendo mais revelador das deficiências do mercado de trabalho e espaço público brasileiros - e menos um mérito de seu rigor acadêmico - que a história pública não articule um campo profissional no país? Mais especificamente, qual a validade de uma concepção de história pública definida a partir "de dentro", a partir dos limites da historiografia disciplinar e dos profissionais já estabelecidos, para alunas e alunos que, cada vez mais, atuarão "para fora" da academia?

Para responder essas questões, ofereço os encaminhamentos que se seguem. Eles são naturalmente provisórios e se constituem, até o momento, num "plano de ação" individual e ainda não concretizado. Ao publicizá-lo, faço o convite às leitoras e leitores para avaliarem sua pertinência e, se possível, incorporá-lo em sua prática. Também é preciso destacar que os apontamentos são, devido à minha formação e ao caráter desta publicação, relativos à historiografia acadêmica. Eles são uma tentativa feita a partir de "dentro" para se comunicar com o que está "lá fora".

Em primeiro lugar, reconhecer a pluralidade das formas de atuação de historiadoras e historiadores. Isso implica não somente a necessidade de realizar mapeamentos das oportunidades oferecidas aos egressos dos cursos de história, mas também reformular como se entende o significado da formação para sua 
identidade profissional. Em certo sentido, o historiador holandês Herman Paul (2011; 2014) tem procurado pensar isso, ao adotar as categorias de "personas acadêmicas" e "virtudes epistêmicas", emprestadas dos estudos da ciência; Fernando Nicolazzi (2018), no Brasil, deu um passo além, ao mostrar como a construção subjetiva enquanto historiador é, na verdade, intersubjetiva, dependente de ocasião e público. O resultado seria uma passagem do que as historiadoras e historiadores são para o que fazem, aliado à constatação de que essas "artes do fazer" são extremamente variadas.

Depois, reconquistar a subjetividade do espectro do neoliberalismo, no sentido de que é possível atuar como historiadora ou historiador mesmo em contextos predominantemente mercadológicos; do mesmo modo, um pouco de empreendedorismo não seria negativo, caso se entenda que o mercado e a iniciativa privada também são parte do nosso espaço público. Como seria se assumíssemos postura propositiva, e não somente reativa, a eles? Além disso, não é meritório que desejemos contribuir para a circulação de enunciados históricos mais responsáveis em todos os espaços que pudermos? Na minha opinião, isso implicaria reconhecer, como faz Xavier Rousseaux, que "a história é uma formação antes de um métier" e, portanto, "historiadores e historiadoras serão sempre historiadores e historiadoras não importa qual sua profissão." (ROUSSEAUX, 2005, p. 136-137).

Um resultado seria, na sequência, a transformação de valores neoliberais em valores das humanidades. Penso que a história pública tem muito a contribuir aqui, afinal, ecoando as palavras de Santhiago, não se trata de oferecer uma perspectiva normativa, mas de abrir um horizonte de ação. Mais concretamente, poderia resultar na valorização do bacharelado em história, atualmente tão mal definido. A história pública auxiliaria na introdução de "habilidades" e "competências" que nos ajudassem a atuar junto ao público. Não creio que a história pública deva ser um conjunto de conteúdos - comunicação visual, design, programação, atuação, gravação de som, edição de vídeo etc. -, mas ela pode contribuir para a preparação de historiadoras e historiadores para novos modos de trabalho que sejam (e serão) colaborativos, por demanda e vinculados a projetos. O propósito seria que o bacharel em história se transformasse num gestor de projetos de história, não muito distante da ideia de "curadoria do 
passado" desenvolvida recentemente por Valdei Lopes de Araujo (2017) ou da proposta de Marcelo Téo (2018) para remediar o que ele denomina "desequilíbrio de histórias".

Por último, o problema da relevância do conhecimento histórico, anunciado no começo do artigo, passa pela necessidade de repensar sua justificativa num momento no qual o conceito moderno de história perdeu sua obviedade e muito de sua efetividade. Diversos autores já apontaram a transformação do tempo histórico nas últimas décadas; do debate, o que me interessa é o fim da associação entre a passagem do tempo e o progresso e, logo, da cumplicidade entre o conhecimento histórico e o conceito moderno de história pelo prisma da emancipação. Agora que essas noções estão desvinculadas, historiadoras e historiadores se encontram sujeitos a ataques sem poder recorrer ao futuro ou ao "lado certo da história" para auxiliá-los a resgatar sua autoridade. A pertinência do saber histórico em sua capacidade de contribuir para a justiça social será avaliada, daqui para a frente, caso a caso e, mais importante ainda, será sempre uma questão pública.

Eu não poderia encerrar essa reflexão sem agradecer a todas e todos que contribuíram para sua elaboração através do diálogo e de suas inquietações. A elas e eles, não sei se ofereço respostas, mas, como diz a música, posso conceder minha presença, ainda que confusa, leal e intensa ${ }^{5}$. Talvez seja o caso de, após os debates sobre a entrada e a permanência na universidade, transformar o meio acadêmico numa morada receptiva o bastante para receber de volta aquelas e aqueles que, pelas pressões do mundo contemporâneo, tiverem de "abandoná-lo".

\footnotetext{
${ }^{5}$ Antes de encerrar este texto, gostaria de nomear os amigos e amigas, colegas e companheiros, com quem tive a oportunidade de compartilhar as ideias deste texto ao longo de sua elaboração, em especial Raymara Santos, cuja inquietação pessoal foi o principal motivo para a escrita destas páginas. Também gostaria de agradecer Diego Paim de Souza, Francieli Daiane Borges, Renata da Conceição Aquino da Silva, Luciana Portella Kohlrausch, Fernando Seffner, Marina Bezzi, Mauro Franco Neto e as alunas e alunos do curso de História da Universidade Federal de Santa Maria, que gentilmente me convidaram para uma fala no II Congresso de Ensino, Pesquisa e Extensão em História em 2019. Dentre estes, quero lembrar de Pedro Leal Gomes, Carolina Orquen do Nascimento e Gabrielle de Souza Oliveira, cuja amizade surgiu do convívio acadêmico e se tornaram, como não poderia deixar de ser, referenciais para compreender o novo mundo. A música referenciada é “Vida loka, parte I”, dos Racionais MC's.
} 


\section{Referências}

ANTUNES, Ricardo. O privilégio da servidão: o novo proletariado de serviços na era digital. São Paulo: Boitempo, 2018. E-book.

ARAUJO, Valdei Lopes de. O direito à história: O(a) historiador(a) como curador(a) de uma experiência histórica socialmente distribuída. In: GUIMARÃES, Géssica; BRUNO, Leonardo; PEREZ, Rodrigo. Conversas sobre o Brasil: ensaios de crítica histórica. Rio de Janeiro: Autografia, 2017. p. 191-216.

BROWN, Wendy. Undoing the demos: neoliberalism's stealth revolution. New York: Zone Books, 2015.

CRARY, Jonathan. 24/7: capitalismo tardio e os fins do sono. São Paulo: Cosac Naify, 2014.

DARDOT, Pierre; LAVAL, Christian. A nova razão do mundo: ensaio sobre a sociedade neoliberal. São Paulo: Boitempo, 2017.

EHRENBERG, Alain. The weariness of the self: diagnosing the history of depression in the contemporary age. Montreal: McGill-Queen's University Press, 2010.

HAN, Byung-Chul. Sociedade do cansaço. Petrópolis: Vozes, 2019. E-book.

HUWS, Ursula. Labor in the digital economy. New York: Monthly Review Press, 2014.

KEHL, Maria Rita. O tempo e o cão: a atualidade das depressões. São Paulo: Boitempo, 2015.

KOSELLECK, Reinhart. Crítica e crise: uma contribuição à patogênese do mundo burguês. Rio de Janeiro: Contraponto, 1999.

LANGE, Alexandra. The dot-com city: Silicon Valley urbanism. Moscow: Strelka Press, 2012.

LAZZARATO, Maurizio. Signos, máquinas, subjetividades. São Paulo: Edições Sesc São Paulo: n-1 edições, 2014.

LORENZ, Chris. If you're so smart, then why are you under surveillance? universities, neoliberalism, and new public management. Critical Inquiry, [Chicago], v. 38, n. 3, p. 599-629 Spring 2012.

LUCCHESI, Anita. Digital history e storiografia digitale: estudo comparado sobre a escrita da história no tempo presente (2001-2011). 2014. Dissertação (Mestrado 
em História Comparada) - Programa de Pós-Graduação em História Comparada, Universidade Federal do Rio de Janeiro, Rio de Janeiro, 2014.

MOSSI, Thays Wolfarth. O futuro da humanidade que trabalha: reconfiguração moral das lutas trabalhistas frente à terceirização. 2016. Tese (Doutorado em Sociologia) - Instituto de Filosofia e Ciências Humanas, Universidade Federal do Rio Grande do Sul, Porto Alegre, 2016.

NICOLAZZI, Fernando. Muito além das virtudes epistêmicas: o historiador público em um mundo não linear. Revista Maracanan, [Rio de Janeiro], n. 18, p. 18-34, jan./jun. 2018.

NUSSBAUM, Martha C. Not for profit: why democracy needs the humanities. Princeton, NJ: The Princeton University Press, 2016.

PAUL, Herman. Performing history: how storical scholarship is shaped by epistemic virtues. History \& Theory, [Middletown], v. 50, p. 1-19, feb. 2011.

PAUL, Herman. What is a scholarly persona? ten theses on virtues, skills, and desires. History \& Theory, [Middletown], v. 53, p. 348-371, oct. 2014.

PELBART, Peter Pál. O avesso do niilismo: cartografias do esgotamento. São Paulo: n-1 edições, 2013.

ROUSSEAUX Distance et engagement de l'historien. In: ZELIS, Guy. L'historien dans l'espace public: l'histoire face à la mémoire, à la justice et au politique. Loverval: Editions Labor, 2005. p. 129-137.

SANTHIAGO, Ricardo. História pública e autorreflexividade: da prescrição ao processo. Tempo \& Argumento, Florianópolis, v. 10, n. 23, jan./mar. 2018. p. 295296.

SCHMIDT, Benito Bisso. Qual a relação entre a história pública e a profissionalização do historiador? In: MAUAD, Ana Maria; SANTHIAGO, Ricardo; BORGES, Viviane Trindade (orgs.). Que história pública queremos? São Paulo: Letra \& Voz, 2018. p. 17-22.

SHOPES, Linda. A evolução do relacionamento entre história oral e história pública. In: MAUAD, Ana Maria; SANTHIAGO, Ricardo; BORGES, Viviane Trindade. História pública no Brasil: sentidos e itinerários. São Paulo: Letra \& Voz. p. 71-85.

SHORE, Cris; TAITZ, Mira. "Who 'owns' the university? Institutional autonomy and academic freedom in an age of knowledge". Globalisation, Societies and Education, v. 10, issue 2, 2012, p. 201-219. 
SOUZA, Jessé. Os batalhadores brasileiros: nova classe média ou nova classe trabalhadora? Belo Horizonte: Editora da UFMG, 2010.

STANDING, Guy. The Precariat: the new dangerous class. London: Bloomsbury, 2013.

TÉO, Marcelo. Desequilíbrio de histórias, parte I: um problema do campo das humanidades (?). Tempo \& Argumento, Florianópolis, v. 10, n. 23, jan./mar. 2018. p. 361.

TRAVERSO, Enzo. Left-wing melancholia: marxism, history, and memory. New York: Columbia University Press, 2016.

TURIN, Rodrigo. Entre o passado disciplinar e os passados práticos: figurações do historiador na crise das humanidades. Tempo, Niterói, v. 24, n. 2, p. 187-205, maio/ago. 2018.

TURKLE, Sherry. The second self: computers and the human spirit. Cambridge: The MIT Press, 2005.

WHITE, Hayden. El pasado práctico. In: TOZZI, Verónica; LAVAGNINO, Nicolás (eds.). Hayden White, la escritura del pasado y el futuro de la historiografía. Sáenz Peña: Universidad Nacional de Tres de Febrero, 2012. p. 19-39.

ZANDONADI, Viviane. Profissões do futuro: historiadores corporativos. O Estado de São Paulo, São Paulo, 22 jul. 2015. Disponível em:

https://educacao.estadao.com.br/ noticias/geral,profissoes-do-futurohistoriadores-corporativos,1730012. Acesso em: 24 jul. 2020.

Universidade do Estado de Santa Catarina - UDESC

Programa de Pós-Graduação em História - PPGH

Revista Tempo e Argumento

Volume 12 - Número 30 - Ano 2020

tempoeargumento@gmail.com 